\title{
Minimally invasive Fothergill -Manchester operation with connective tissue conservation
}

\author{
Peter Petros ${ }^{1}$, Ray Hodgson ${ }^{2}$, Xiuli $\mathrm{Sun}^{3}$, and Jianliu Wang ${ }^{4}$ \\ ${ }^{1}$ University of Western Australia \\ ${ }^{2}$ University of New South Wales \\ ${ }^{3}$ Peking University Peoples hospital \\ ${ }^{4}$ Affiliation not available
}

November 29, 2021

\begin{abstract}
Our minimally invasive Fothergill-Manchester technique aims to decrease blood loss and surgical trauma and to preserve function by1. Vaginal conservation. 2. Cardinal (CL) and uterosacral (USL) ligaments plicated, not severed. 3. Direct suture of vagina to cervix without Sturmdorf sutures after cervical amputation. 4. Use of No2 polyester sutures to create new collagen to reinforce the plicated ligaments.
\end{abstract}

\section{TITLE}

Minimally invasive Fothergill -Manchester operation with connective tissue conservation

${ }^{1}$ Petros PE* , ${ }^{2}$ Hodgson $\mathrm{R},{ }^{3}$ Sun $\mathrm{X},{ }^{3}$ Wang JL

${ }^{1}$ School of Mechanical and Mathematical Engineering, University of Western Australia, Perth Australia

${ }^{2}$ University of NSW, Sydney Australia.

${ }^{3}$ Obstetrics \& Gynecology Dept. Peking University People's Hospital Beijing 100044 CHINA

* Corresponding Author ${ }^{1}$ Petros PE, ${ }^{1}$ School of Mechanical and Mathematical Engineering, University of Western Australia, Stirling Highway, Crawley,Perth Australia 6009. Email pp@kvinno.com

Tel +61411181731

Running title Minimally invasive Manchester operation

No of words TEXT 1706 Abstract

\section{ABSTRACT}

Our minimally invasive Fothergill-Manchester technique aims to decrease blood loss and surgical trauma and to preserve function by1. Vaginal conservation. 2. Cardinal (CL) and uterosacral (USL) ligaments plicated, not severed. 3. Direct suture of vagina to cervix without Sturmdorf sutures after cervical amputation. 4. Use of No2 polyester sutures to create new collagen to reinforce the plicated ligaments.

\section{INTRODUCTION}

\section{Background}


Poor cure rates for prolapse repair reported by the PROSPECT TRIAL (as low as 26\%) [1] total mesh bans after the Cumberlage Report [2] leave few options for vaginal surgery in the UK. One remaining option, the Fothergill-Manchester Repair began as a modification of the Donald operation [3]. Fothergill emphasized the role of cardinal ligament (CL) and uterosacral (USL) ligaments in uterine prolapse repair [4]. The classical Manchester operation involves full thickness inverted V-shaped vaginal excisions, fig1. The cervix is dilated and if elongated, it is amputated. CLs are severed and sutured to the anterior part of cervix. USLs may also be severed. Sturmdorf sutures bring vaginal flaps into the cervical canal. Vagina is repaired. The operation can be traumatic, with blood loss as high as mean 850ml. [5], possibly related to severing of CLs which contains uterine artery branches and also, failure of Sturmdorf sutures to control bleeding from cervical amputation.

Our less invasive Fothergill repair is based on Fothergill's original vision which emphasized CL/USL as structural components, figs2-6. However, we did not excise vagina, sever CLs or USLs, or use Sturmdorf sutures. We re-attached vagina directly to the amputated cervix. Excess vaginal tissue was re-assigned by suturing the vaginal epithelium onto the deep fascial layer, fig7. We considered that these steps decreased the likelihood of intra-operative and immediate post-operative bleeding.

We describe transverse and vertical vaginal incision methodology. Otherwise, the techniques are identical, each with advantages and disadvantages. The vertical incision method is more familiar for those trained in the traditional Manchester operation. The transverse incision is advantageous as brings the surgeon directly onto the CL and USL ligaments, which are sometimes difficult to locate.

\section{Anatomy and pathogenesis}

At $10 \mathrm{~cm}$ dilation of the cervix, both CL and USL may be stretched or torn because of pressure of the head as it enters the birth canal. In the menopause, further ligament weakness may occur because of collagen break down. CL prolapses down onto the lateral part of the cervix, fig3, and the bladder rotates down like a trapdoor as a cystocele (transverse defect), fig3.

The same $10 \mathrm{~cm}$ cervical dilatation may overstretch the attachments of USL to weaken and elongate them, fig 2 , and separate them laterally to form an enterocele.

It is evident from fig2, that the cardinal ligaments MUST elongate in parallel with uterosacral ligament elongation. Therefore both CL and USL must be repaired, and the fascial layer of vagina re-attached, fig3.

\section{Identification of a prolapsed cardinal ligament.}

Fig3 shows the classical appearance of vagina prolapsing down lateral to the cervix and fig4 where hysterectomy has been performed. Two lateral "dimples" identify the site of the hysterectomy incision.

\section{Proving CL pathogenesis of transverse defect cystocele}

Grasping the displaced CLs with Allis forceps and approximating them medially on the anterior lip of the cervix restores vaginal anatomy. See VIDEO.

\section{Cervical amputation (if required)}

The length of the cervix is estimated by palpating the USL insertions at the posterior cervical ring. Two sutures are placed high above the cervix laterally to tie off the descending uterine arteries. The cervix is amputated, preferably with cutting diathermy, and the vaginal skin is directly attached with interrupted 00 vicryl sutures. (see VIDEO).

\section{SURGICAL TECHNIQUE USING TRANSVERSE INCISIONS}

VIDEO of transverse incision CL repair https://youtu.be/aJDPOELZZfc

VIDEO transverse incision USL repair https://www.youtube.com/watch?v=MGLdYHtqxzg 
Indications for transverse incision The main indication is simplicity of the surgery, ideal for women with minimal prolapse. CLs and USLs are much easier to locate as the transverse incision brings the surgeon virtually on top of the laterally displaced ligaments. This USL plication technique, fig5, was used in 1996 to address chronic pelvic pain in women with apical prolapse, with $70 \%$ cure at 12 months [6]. The pain was hypothesized to originate from insufficient support of the pelvic visceral plexuses by lax USLs [6].

\section{Transverse incision cardinal ligament (CL) plication.}

All steps in the surgery are performed with the vagina stretched and under tension. The cervix is grasped with a tenaculum and pulled towards the surgeon. Under tension, a transverse incision is made $1 \mathrm{~cm}$ above the cervix or hysterectomy scar. The bladder is dissected off the cervix or vagina (with previous hysterectomy), initially with dissection scissors, then with finger dissection to expose the anterior cervix and push ureters away from the field of surgery. With previous surgery, the scar may be very adherent to bladder. Grasp bladder wall with forceps to create counter tension to vagina to facilitate entry to the right dissection plane.

The CL ligaments are located at 9 and 3 o'clock. Tensioning the lateral ends of the vaginal incision helps locate CLs. A strong band at 3 and 9 o'clock identifies CLs which are approximated to the midline with two polyester *sutures (fig 3).

*No2 polyester creates a collagen reaction which will help reinforce the ligament. The collagen1created has a breaking strain of $18,000 \mathrm{lbs} / \mathrm{sq}$ inch and may be sufficient to create a longer-term result. Clearly it is not as collagenopoietic as a 7-10 mm polypropylene tape which can no longer be used in many countries.

If CLs cannot be accurately located, take a No2 polyester suture 1-1.5cm inferolaterally on each side, "S", fig 3, and approximate. The tissues taken up are invariably attached to CLs

Re-attachment of musculofascial layer of vagina to the approximated cardinal ligaments is best done with a purse-string suture $1 \mathrm{~cm}$ from the cut edge with 00 vicryl (see VIDEO).

Push the vagina down to the CL suture and tie the purse string deep into the vagina onto CL Close vaginal skin with 00 Vicryl.

\section{Transverse incision uterosacral ligament (USL) plication.}

The cervix is grasped with a tenaculum.

Forceps are placed $5 \mathrm{~cm}$ apart $3-4 \mathrm{~cm}$ below cervix or hysterectomy scar (fig5) at apex of enterocele, stretched towards the surgeon, and a $5 \mathrm{~cm}$ transverse incision is made. Inserting a Sims speculum helps open out the incision. With major prolapse, USLs are often laterally located. Stretching vagina facilitates identification, generally at 2 and 10 o'clock.

The enterocele is gently dissected off the vagina but not entered. The USLs are grasped with strong forceps, penetrated and approximated using a No2 polyester suture, fig5to close the enterocele without opening it. Attachment of rectovaginal fascia to USLs is made with a purse-string suture $1 \mathrm{~cm}$ from the cut vaginal edge (VIDEO) then tied deep into the already approximated USLs. Vagina is closed with 00 vicryl.

If the ligaments cannot be accurately located, take two sutures laterally beyond the vaginal incisions and approximate. The tissues taken up are invariably attached to the

ligaments and the sutures will approximate them.

\section{SURGICAL CL/USL REPAIR USING VERTICAL INCISIONS}

VIDEO repair CL/USL with vertical vaginal incisions using No2 polyester sutures.

Vertical incisions are more familiar for those familiar with the traditional Manchester operation. The surgical methodology as regards dissection and ligament repair is identical to that for transverse incisions. The vertical CL operation repairs a high cystocele (transverse defect) and reconstructs the CLs of the prolapsed uterus 
exactly as does the transverse incision. The cervix is grasped with a tenaculum. A full thickness vertical incision is made from cervix to $1 \mathrm{~cm}$ short of the bladder neck. The bladder is dissected off the vagina and cervix. CLs are identified and approximated with No2 polyester sutures.

A central defect is higher up, just below bladder neck, fig6. excess vaginal tissue is not excised, but repaired by the vaginal conservation technique, fig 7 .

\section{Is cystoscopy indicated after CL/USL plication to exclude ureteric kinking?}

Though the technique described has built-in safety as regards kinking the ureter, it is preferable to perform cystoscopy to check ureters are working

\section{Discussion}

Ligaments for structure, vagina for function The differential biomechanics of ligaments (structure) and vagina (function) endorse the intuition of Fothergill in making CL and USL repair key parts of his operation. Tissue biomechanics explain poor results for prolapse with vaginal repair only [1]. Ligaments $300 \mathrm{mg} / \mathrm{mm}^{2}[7]$ are the main structural support of the uterus while the more elastic vagina $60 \mathrm{mg} / \mathrm{mm}^{2}$, transmits the muscle forces to close and open the urethra, and to stretch the vagina to control the afferent impulses from the urothelial stretch receptors [8].

Vaginal conservation The vagina is an organ. Once its collagen and elastin are excised, they cannot be regenerated. Rather than excision, excess vaginal tissue can be easily re-assigned, fig7. The cut edge of epithelium is brought down onto the fascia below, in effect, compressing the loose tissue. Within a few weeks the component collagen and glycosaminoglycans which constitute the structural elements of the vagina re-order the tension within the vaginal tissue, so by 6 weeks review, vaginal appearance appears normal. Excision and scarring may fibrose the vagina sufficiently to cause the "Tethered Vagina Syndrome" (TVS) [9], which may cause massive urine loss, characteristically on getting out of bed in the morning. TVS can only be repaired by a skin graft to the vagina.

Minimizing excision of tissues reduces bleeding. By conserving vagina, not hiding potential bleeding points on the cervix behind Sturmdorf sutures, not transecting CL, many potential bleeding points are avoided.

Native ligament repair does not work well after the menopauseShkarupa et al. published native ligament repair data for CL/USL much as described here, in two cohorts, premenopausal and postmenopausal [10]. By 18 months, good results for cure of prolapse, OAB (urge, frequency, nocturia) were obtained at 3,6,12,18 months, Table 1, but only for the premenopausal cohort. A massive stepwise deterioration in symptoms and prolapse occurred by 18 months, Table1. The authors concluded that the cause for the rapid deterioration was collagen breakdown in the ligaments [10]. They recommended cardinal/USL slings in postmenopausal women.

Use of No2 polyester. The midurethral sling's success in curing stress urinary incontinence is based on harnessing the collagenopoietic effect of an implanted polypropylene tape to structurally reinforce weakened pubourethral ligament [11]. The collagen created, collagen I, has a breaking strain of 18,000 lbs / sq inch[11]. It follows, not much collagen is required to reinforce a ligament $0.5-0.7 \mathrm{~mm}$ in diameter. Our aim in using a thick No2 polyester suture was to create new collagen to reinforce the native tissue ligament repair.

Conclusions The minimally invasive repair faithfully follows the Fothergill principle of ligament repair, suitably modified to conserve tissue, reduce bleeding and hopefully, to provide longer term cure.

Contributions Surgery VIDEOS PP RH XS. Planning PP RH XS Analysing PP RH XS WJL Writing PP RH XS

Conflict of interest NIL for any author.

Ethics Not applicable. These are standard hospital operations for all authors. 


\section{Funding NIL}

\section{Acknowledgments}

Professor Sekiguchi for the cervical amputation video.

Professor Shkarupa for Table1.

\section{References}

1. Glazener CMA, Breeman S, Elders A, Hemming C, Cooper KG, Freeman RM, et al. (for the PROSPECT study group) Mesh, graft, or standard repair for women having primary transvaginal anterior or posterior compartment prolapse surgery: two parallel-group, multicentre, randomised, controlled trials (PROSPECT) LANCET 2016 Published Online December 20, 2016 http://dx.doi.org/10.1016/ S0140-6736(16)31596-3

2. Baroness Cumberlage Report. The Independent Medicines and Medical Devices Safety Review Written Evidence Clinicians, Academics and Other Individuals - Pelvic Mesh Published December 2018.

3. Donald, A. Journ. Obstet. and Gynaecol. Brit. Emp., March, 1908.

4. Fothergill WE. Pathology \& the operative treatment of displacements of the pelvic viscera. Journal of Obstets \& Gynaecol of the British Empire, 1907) 13:410-419.

5. Buchman, M. I. (1953). Blood loss during gynecological operations Amer. J. Obstet. Gynec., 65, 53.

6. Petros PE. Severe chronic pelvic pain in women may be caused by ligamentous laxity in the posterior fornix of the vagina. Aust NZ J Obstet Gynaecol. 1996;36(3):351-354.

7. Yamada H. Aging rate for the strength of human organs and tissues. Strength of Biological Materials, Williams \& Wilkins Co, Balt. (Ed) Evans FG. (1970); 272-280.

8. Liedl B, Inoue H, Sekiguchi Y, Gold D, Wagenlehner F, Haverfield M, Petros P. Update of the Integral Theory and system for management of pelvic floor dysfunction in females. Eur J Urol. EURSUP-738. http://dx.doi.org/10.1016/j.eursup.2017.01.001

9. Williams G Browning A Petros PE The integral theory and its tethered vagina syndrome visited: vaginal scarring may cause massive urinary incontinence BJU Int 2018 Oct;122(4):532-534. doi: 10.1111/bju.14218. Epub 2018 Apr 23.

10. Shkarupa D, Zaytseva A, Kubin N, Kovalev G, Shapovalova E. Native tissue repair of cardinal/uterosacral ligaments cures overactive bladder and prolapse, but only in pre-menopausal women. Cent European J Urol. 2021;74:372-378.

11. Petros PE, Development of the midurethral sling for stress urinary incontinence, Doctor of Surgery Thesis 1999, University of Western Australia.

Fig1. Vaginal incisions for classical and minimally invasive Manchester operations. Note the classical Manchester takes the incision to within $1.5 \mathrm{~cm}$ of the urethra "U" and around cervix "CX". The minimal vertical incision method is always $1 \mathrm{~cm}$ below bladder neck, in order to avoid "tethered vagina syndrome". A=anus.

Fig2 Anatomy of uterine prolapse

Uterosacral (USL) and cardinal (CL) ligaments overstretched at childbirth or weakened by collagen loss after the menopause cannot support the uterus, so it prolapses. Clearly both CL and USL need to repaired during reconstructive surgery.

Fig3 Identifying and suturing laterally displaced cardinal ligaments.

Left figure Displaced cardinal ligament's (CL) The dilatation by the head to $10 \mathrm{~cm}$ has fractured the CL's attachment to the cervix and displaced it laterally. Also torn is the pubocervical facsia (PCF) attachment of vagina to CL. The vagina now rotates downwards like a trapdoor to cause cystocele ("transverse defect"). The sutures "S" re-attach CL to the cervix.

Right figure Identifying a dislocated CL. The cervix (CX) is pulled to the right to show the vagina on the lateral wall of CX 
Fig4. CL dislocation with prior hysterectomy. Broken lines =hysterectomy scar, identified by "dimples". $\mathrm{E}=$ enterocele; Arrow indicates the bulge of the dislocated cardinal ligament (CL).

Fig5 Approximation of uterosacral ligaments (USL). Schematic view into the vagina. A transverse incision (broken red lines) is made at the apex of the enterocele or $4 \mathrm{~cm}$ below the cervix or hysterectomy scar. The incision is opened out (broken diamond-shaped lines) and USLs are located A strong needle with No2 polyester suture is inserted laterally to at least $1 \mathrm{~cm}$ depth, taking a segment of tissue. This suture is held and another suture is inserted. The sutures are approximated. USL=uterosacral ligament.

Fig6 Central cystocele is shiny and usually accompanies a transverse defect cystocele. Broken lines with arrows indicate ruptured and prolapsed cardinal ligaments. $\mathrm{BN}=$ bladder neck. $\mathrm{CX}=$ cervix.

Fig7 Re-attachment of dislocated vaginal epithelium to underlying fascia with continuous or interrupted fascial attachment suture. Excess vaginal tissue was shrunken by suturing the vaginal epithelium onto the deep fascial layer. With each suture, the fore and middle fingers are placed around the descending suture, to push down the vaginal epithelium into the fascia.

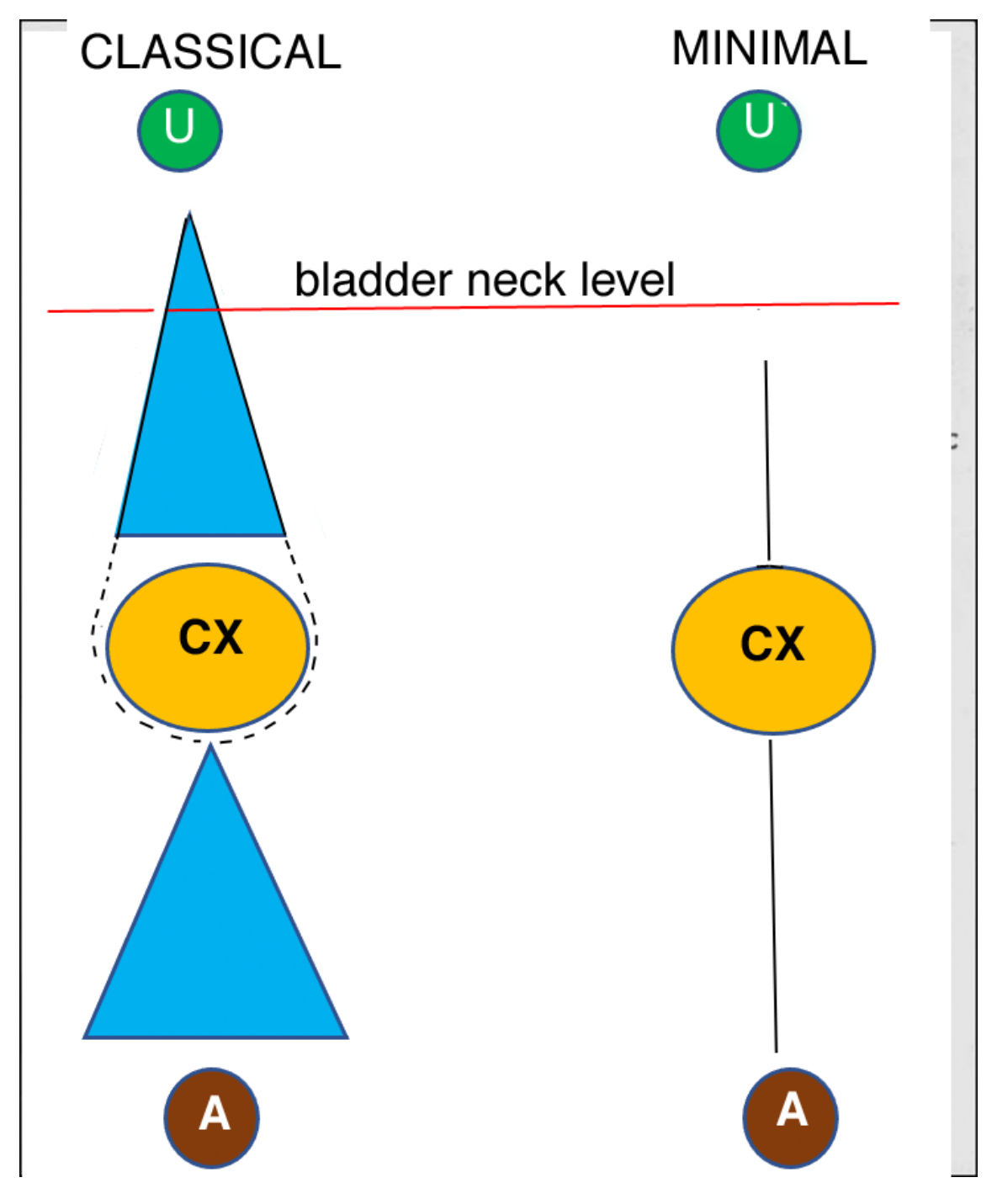



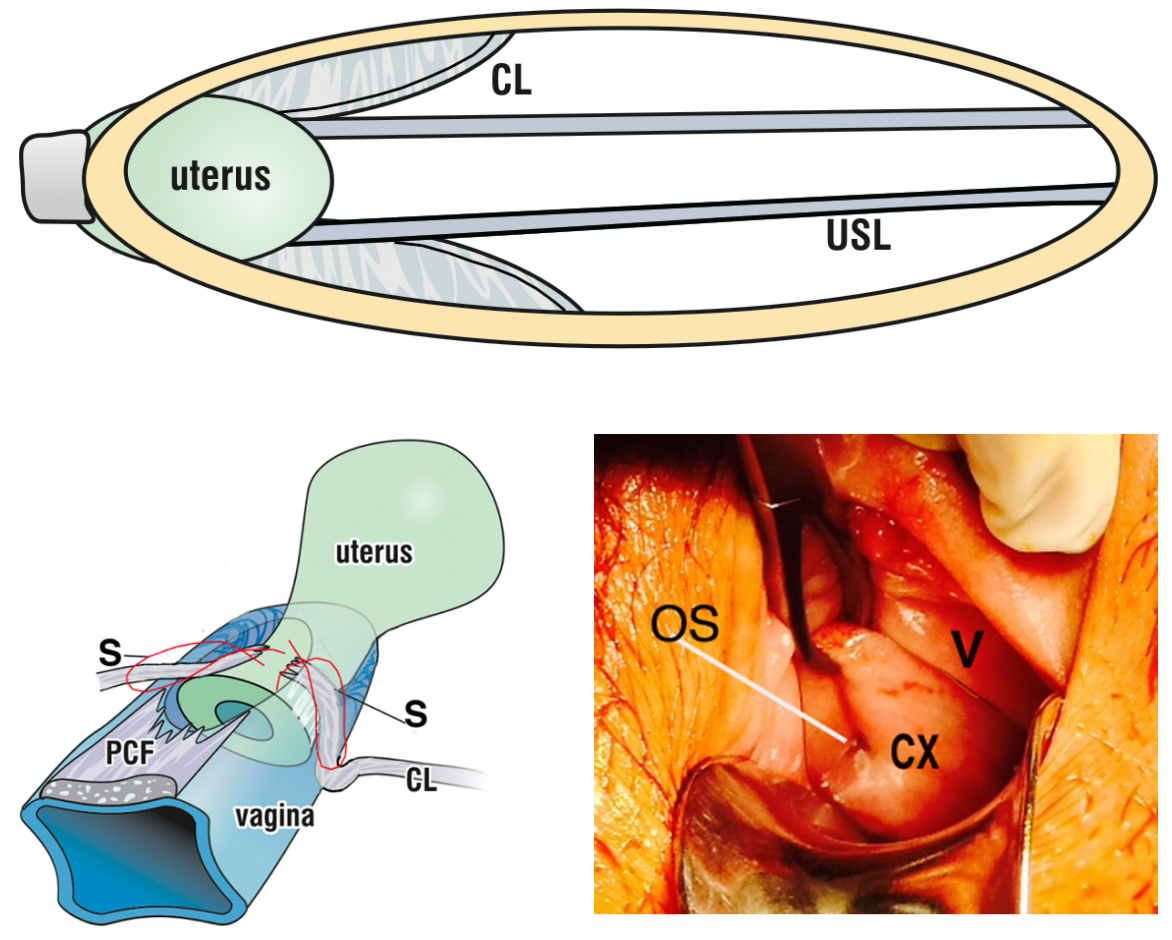


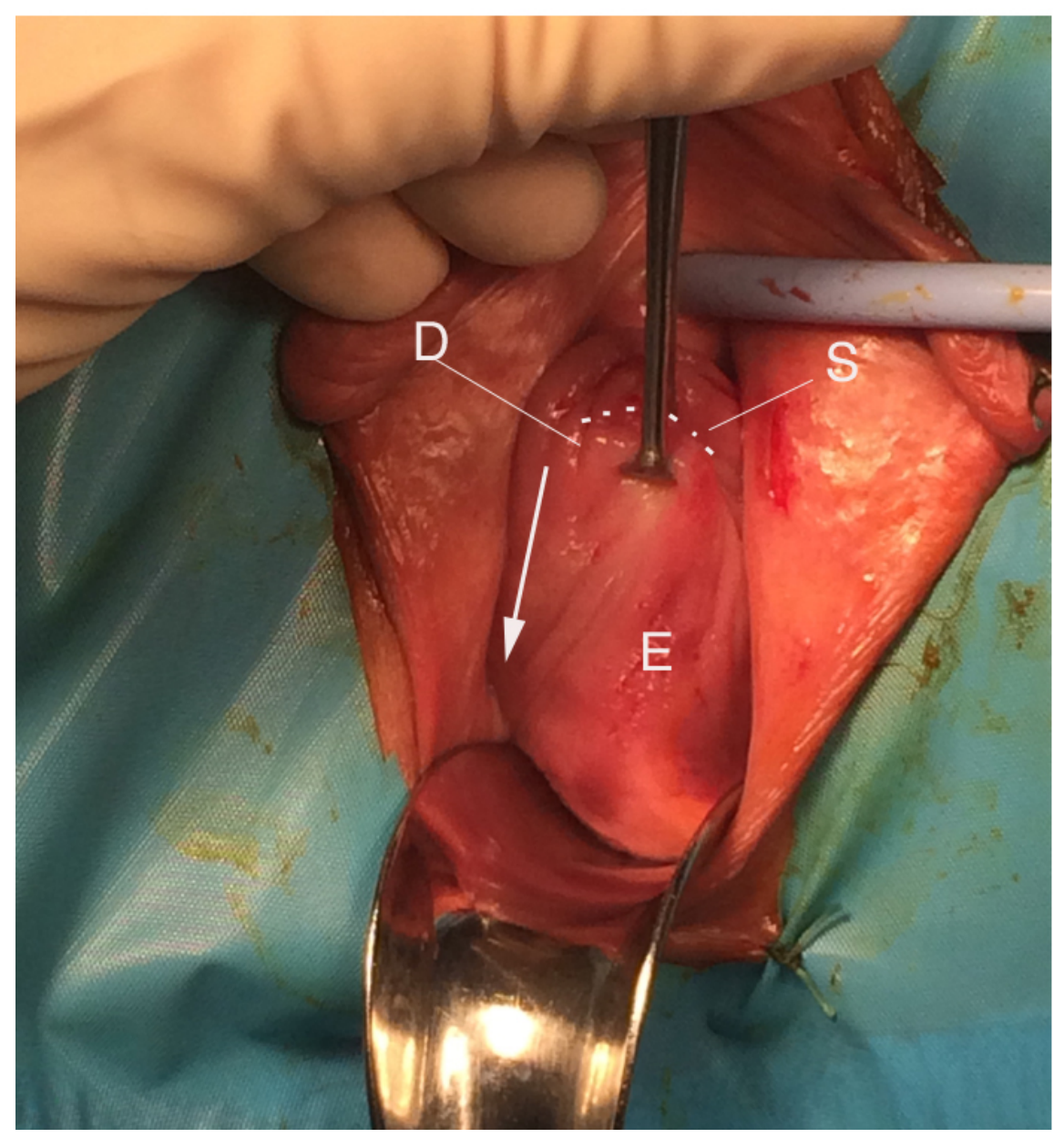




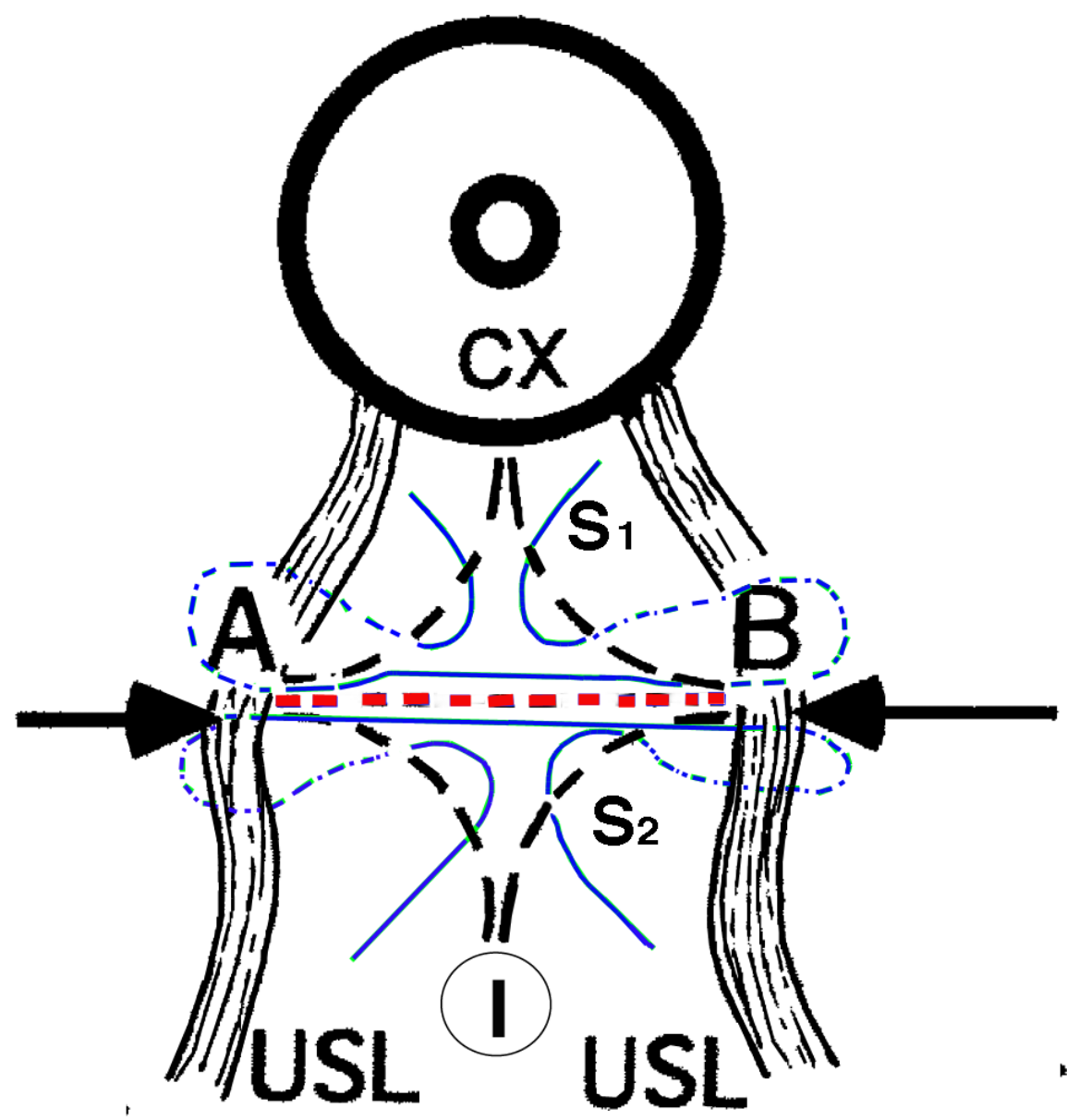




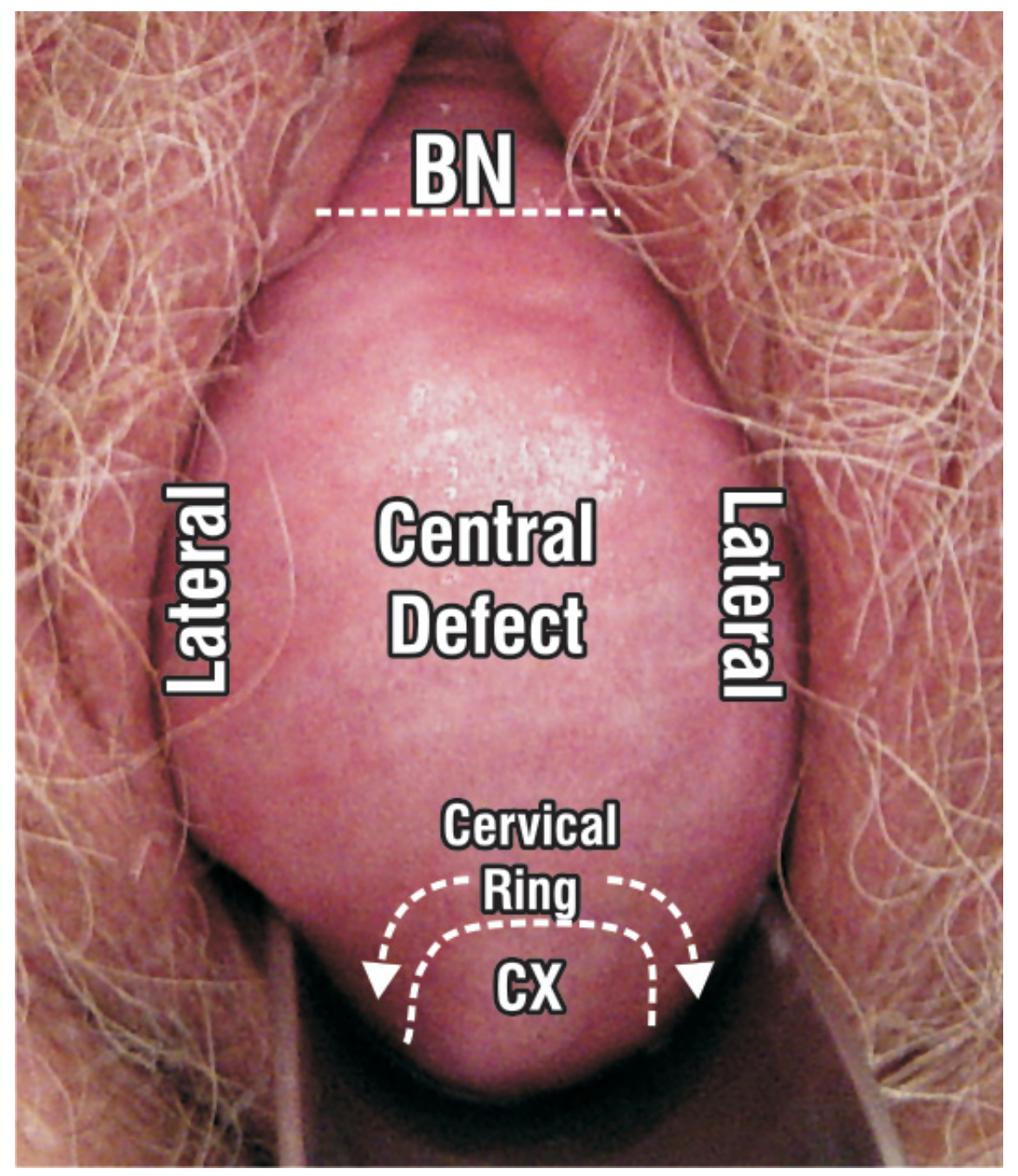



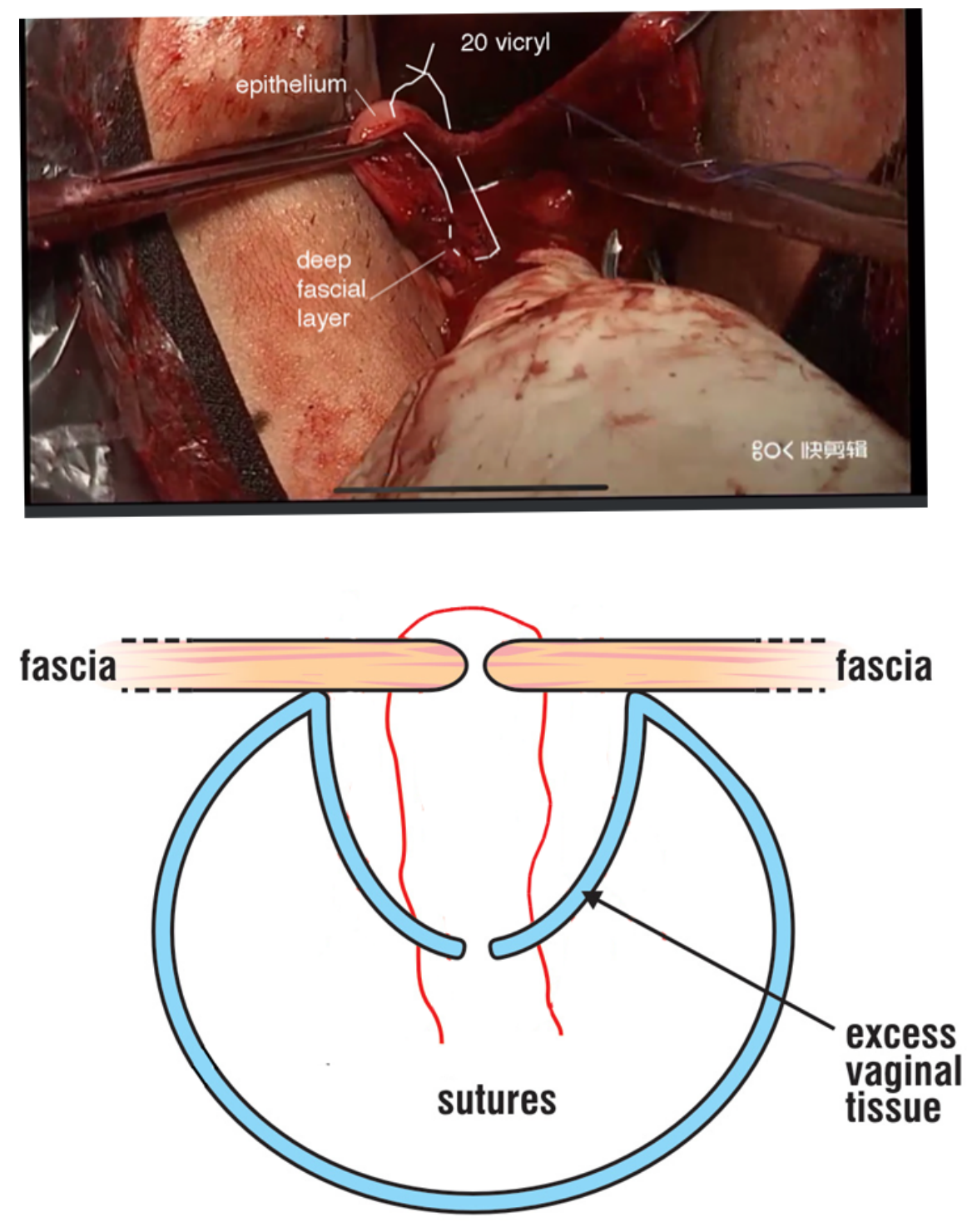